\title{
Capture of Carbon Dioxide by Cucurbit[7]uril Complex
}

\author{
Li LIU \\ Dalian University of Technology \\ Dalian, Liaoning, 116024, China \\ e-mail: 1liu@dlut.edu.cn
}

\begin{abstract}
A supramolecular approach to $\mathrm{CO}_{2}$ capture by cucurbit[7]uril (CB[7]) complex was developed. $\mathrm{NH}_{2}\left(\mathrm{CH}_{2}\right)_{6} \mathrm{NH}_{2} \subset \mathrm{CB}[7]$ complex can convert $\mathrm{CO}_{2}$ to bicarbonate product exclusively and faster in solution due to the deshielding effect, thereby providing a green absorbent to $\mathrm{CO}_{2}$ with regard to high stability, non-corrosiveness and convenient transportation.
\end{abstract}

Keywords-carbon dioxide; cucurbituril; capture; supramolecular catalysis

\section{INTRODUCTION}

$\mathrm{CO}_{2}$ capture and fixation have called worldwide attention not only due to the increasing environmental concerns, but also in view of the carbon resource utilization [1]. Traditional sorbents of $\mathrm{CO}_{2}$ include aqueous amines, which react with $\mathrm{CO}_{2}$ rapidly at room temperature and can be released easily by gentle heating $\left(60-110^{\circ} \mathrm{C}\right)$ or simply by addition of $\mathrm{HCl}$ or TFA [2]. This reversible conversion leads to controllable capture and release of $\mathrm{CO}_{2}$ from gas streams. However most of the amines are corrosive to equipment and degrade through oxidation [3], which severely restricts the wide application in $\mathrm{CO}_{2}$ capture. To solve the problems, amine-modified solid sorbents supported on silica gels [4], molecular sieves and polymers [5] have been designed and synthesized. Herein we introduced a new supramolecular approach to capture $\mathrm{CO}_{2}$ by cucurbituril complex, in combination with reversible $\mathrm{CO}_{2}$-amine reaction [6].

Cucurbit[n]urils (CB[n]) have become important supramolecular macrocyclic hosts after crown ether, cyclodextrin and calixarene [7]. Ever since Mock firstly reported that 1,3-dipolar cycloaddition could be accelerated by a factor of $5.5 \times 10^{4}$ under the influence of $\mathrm{CB}$ [6] [8], applications of $\mathrm{CB}[\mathrm{n}]$ as catalyst have been investigated in a variety of reactions, such as hydrolysis, solvolysis, desilylation, thiol-disulfide interchange, H/D exchange, oxidation and photoreactions [9]. Due to the complexation within CB cavity, chemical reactivity of the guests could be altered, resulting in rate change, selectivity change and even new products.

In virtue of the unique characteristics of recognition and assembly for supramolecular macrocyclic host structures, amine-modified calixarene [10] and crown ethers [11] have been designed for construction of novel nanostructures and materials. In this work, we revisited the $\mathrm{CO}_{2}$-amine chemistry and developed supramolecular approach to $\mathrm{CO}_{2}$ capture catalyzed by $\mathrm{CB}$ [7] (Figure 1), without resort to the chemical modification step of amino group.

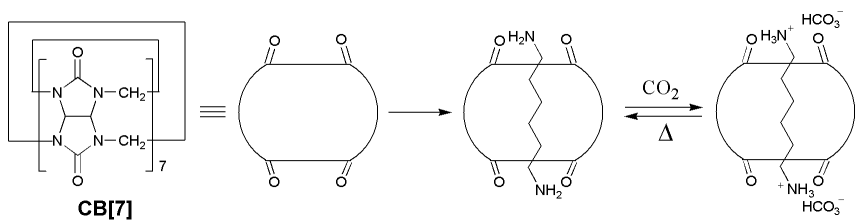

Figure $1 . \mathrm{CO}_{2}$ capture by $\mathrm{CB}[7]$-amine complex.

\section{EXPERIMENTAL}

\section{A. Materials and Apparatus}

Cucurbit[7]uril was synthesized using a published procedure [12] and characterized by NMR prior to use. The highly pure $\mathrm{CO}_{2}(99.999 \%)$ was obtained from local supplier. ${ }^{1} \mathrm{H}$ and ${ }^{13} \mathrm{C}$ NMR spectra were recorded on Bruker DRX-400 spectrometer for ${ }^{1} \mathrm{H}$ at $400 \mathrm{MHz}$ and for ${ }^{13} \mathrm{C}$ at $100 \mathrm{MHz}$.

\section{B. Preparation of the CB[7] Complex}

$\mathrm{NH}_{2}\left(\mathrm{CH}_{2}\right)_{6} \mathrm{NH}_{2} \subset \mathrm{CB}[7]$ complex was readily prepared by mixing solid $\mathrm{CB}[7]$ (100 mg) with excess of 1,6hexanediamine $(2.000 \mathrm{~g})$ at $50{ }^{\circ} \mathrm{C}$ for $3.5 \mathrm{~h}$. After filtration, the uncomplexed amine was washed out thoroughly with methanol. The white powder was dried under vacuum at 70 ${ }^{\circ} \mathrm{C}$ for $3 \mathrm{~h}$ (49\% yield based on $\left.\mathrm{CB}[7]\right)$.

\section{C. $\mathrm{CO}_{2}$ Reaction in Aqueous Solution}

$\mathrm{NH}_{2}\left(\mathrm{CH}_{2}\right)_{6} \mathrm{NH}_{2}$ or $\mathrm{NH}_{2}\left(\mathrm{CH}_{2}\right)_{6} \mathrm{NH}_{2} \subset \mathrm{CB}$ [7] complex (0.004-0.05 M) was dissolved in $\mathrm{D}_{2} \mathrm{O}$ in a $5 \mathrm{~mm}$ NMR tube. $\mathrm{CO}_{2}$ was then bubbled through the solution at $25{ }^{\circ} \mathrm{C}$ with a flow rate of $10 \mathrm{~mL} / \mathrm{min}$ as regulated by flow meter. The $\mathrm{CO}_{2}$ reactions were monitored by ${ }^{\mathrm{T}} \mathrm{H}$ and ${ }^{13} \mathrm{C}$ NMR spectra.

\section{RESUltS AND DISCUSSION}

As reported, amine reacts with $\mathrm{CO}_{2}$ to form carbamate by nucleophilic reaction as in Eq. (1) and bicarbonate by acidbase neutralization as in Eq. (2), whereas decomposition of carbamate with excess of $\mathrm{CO}_{2}$ also leads to bicarbonate as in Eq. (3) [2]. The reactions of amines with $\mathrm{CO}_{2}$ in water for a long time are inclined to form bicarbonate as primary product, however the conversions are hardly complete with a little side product of carbamate, for they are equilibrium reactions. In our model experiment, $\mathrm{NH}_{2}\left(\mathrm{CH}_{2}\right)_{6} \mathrm{NH}_{2}$ reacted with $\mathrm{CO}_{2}$ in aqueous solution, leading to carbamate product first and then bicarbonate, which were demonstrated by the appearance of carbonyl signals on ${ }^{13} \mathrm{C}$ NMR spectra at $\delta$ 164.5 and 159.9 ppm, respectively. 


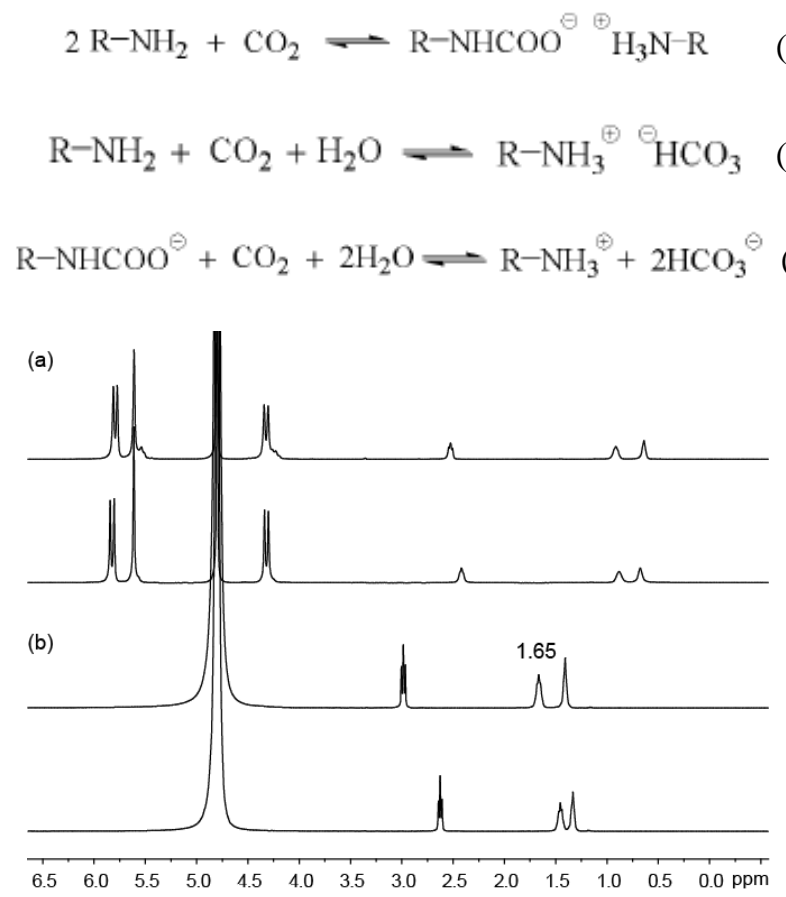

Figure 2. ${ }^{1} \mathrm{H}$ NMR spectra of (a) $\mathrm{NH}_{2}\left(\mathrm{CH}_{2}\right)_{6} \mathrm{NH}_{2} \subset \mathrm{CB}$ [7] and (b) $\mathrm{NH}_{2}\left(\mathrm{CH}_{2}\right)_{6} \mathrm{NH}_{2}$ in $\mathrm{D}_{2} \mathrm{O}$ before (bottom) and after (top) bubbling $\mathrm{CO}_{2}(10$ $\mathrm{mL} / \mathrm{min}$ ) to give the final bicarbonate products.

In contrast, the $\mathrm{NH}_{2}\left(\mathrm{CH}_{2}\right)_{6} \mathrm{NH}_{2} \subset \mathrm{CB}$ [7] complex was synthesized and characterized by ${ }^{1} \mathrm{H}$ NMR (Figure 2), where 1:1 host-guest ratio could be derived from the integration and the resonance signals assigned to amine moving upfield indicate their positioning within the cavity of $\mathrm{CB}$ [7]. For reaction of $\mathrm{NH}_{2}\left(\mathrm{CH}_{2}\right)_{6} \mathrm{NH}_{2} \subset \mathrm{CB}$ [7] complex with $\mathrm{CO}_{2}$ in aqueous solution, the new resonance signal on ${ }^{13} \mathrm{C}$ NMR spectrum at $\delta 159.8 \mathrm{ppm}$ was assigned to bicarbonate as the only product of $\mathrm{CO}_{2}$ fixation, while carbamate product was not detected.

To further verify the different reaction pathways for bound amine and free amine, $\mathrm{NH}_{2}\left(\mathrm{CH}_{2}\right)_{6} \mathrm{NH}_{2} \subset \mathrm{CB}$ [7] complex was mixed with $\mathrm{NH}_{2}\left(\mathrm{CH}_{2}\right)_{6} \mathrm{NH}_{2}$ in $1: 1$ ratio, whereby their reaction processes with $\mathrm{CO}_{2}$ have been monitored in one pot by ${ }^{1} \mathrm{H}$ NMR (Figure 3 ). It was found that component of $\mathrm{NH}_{2}\left(\mathrm{CH}_{2}\right)_{6} \mathrm{NH}_{2}$ reacted with $\mathrm{CO}_{2}$ to form carbamate predominantly at $45 \mathrm{~s}$, which nearly transformed to bicarbonate at $70 \mathrm{~s}$ (Figure 3a). The proton signals of bicarbonate product corresponding to free amine shifted from $1.35,1.46,2.65 \mathrm{ppm}$ to $1.39,1.65,2.98 \mathrm{ppm}$, among which the signal at $1.65 \mathrm{ppm}$ was diagnostic of the bicarbonate formation (Figure 2). Figure $3 \mathrm{~b}$ shows the yield of bicarbonate product for free amine increased from $25 \%$ at $45 \mathrm{~s}$ to above $90 \%$ at $70 \mathrm{~s}$ based on integration of the resonance signal at $1.65 \mathrm{ppm}$, while the yield of carbamate intermediate decreased accordingly based on integration of the resonance signal at $1.25-1.52 \mathrm{ppm}$ deducted by that at $2.98 \mathrm{ppm}$. However for component of $\mathrm{NH}_{2}\left(\mathrm{CH}_{2}\right)_{6} \mathrm{NH}_{2} \subset \mathrm{CB}$ [7] complex, still no carbamate intermediate could be detected under the same concentration. The proton signals of bicarbonate product corresponding to bound amine shifted from $0.67,0.86,2.37 \mathrm{ppm}$ to $0.61,0.89,2.51 \mathrm{ppm}$, whereas the signal shifts appeared and the conversion stayed complete since $45 \mathrm{~s}$ based on integration of the resonance signal at $0.61,0.89$ or $2.51 \mathrm{ppm}$ (Figure 3b), suggesting a different reaction pathway not involving intermediate of carbamate.

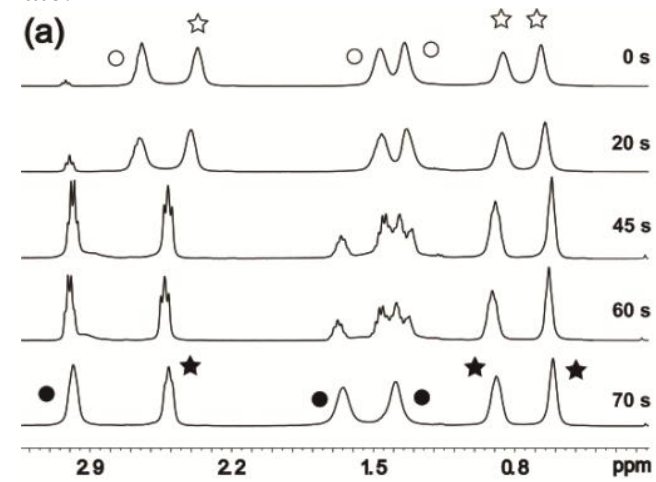

(b)

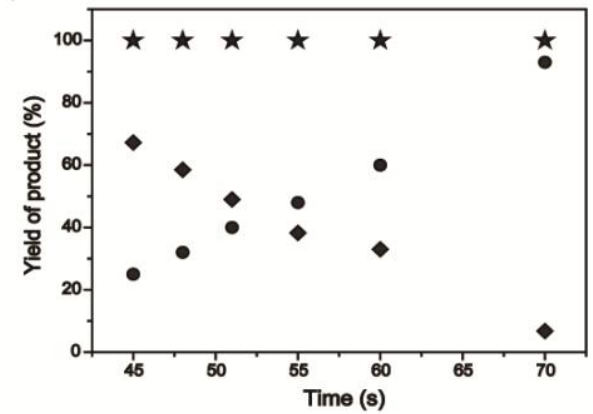

Figure 3. (a) ${ }^{1} \mathrm{H} N M R$ spectra of $\mathrm{NH}_{2}\left(\mathrm{CH}_{2}\right)_{6} \mathrm{NH}_{2} \subset \mathrm{CB}$ [7] and $\mathrm{NH}_{2}\left(\mathrm{CH}_{2}\right)_{6} \mathrm{NH}_{2}(1: 1,0.05 \mathrm{M})$ in $\mathrm{D}_{2} \mathrm{O}$ when bubbling $\mathrm{CO}_{2}(10 \mathrm{~mL} / \mathrm{min})$. Signals for free amine (O), bound amine $(\tau)$ and their bicarbonate products (in solid form) are highlighted. (b) Yields of carbamate product ( $)$ and bicarbonate product $(\bullet)$ for free amine, and bicarbonate product $(\star)$ for bound amine vs time.

The absence of carbamate product for bound amine whether or not in a mixture with free amine could be mostly ascribed to the deshielding effect $[13,14]$ in that nucleophilicity of bound amine to attack $\mathrm{CO}_{2}$ decreases as influenced by the electronegative portal oxygens, while the steric effect also inhibits the formation of carbamate to some extent. On the other hand, increased electrophilicity of bound amine caused by the deshielding effect favors the acid-base neutralization towards bicarbonate product, thus resulting in higher selectivity and faster reaction rate for bound amine compared to free amine.

\section{CONCLUSIONS}

In summary, a supramolecular approach to $\mathrm{CO}_{2}$ capture catalyzed by $\mathrm{CB}$ [7] was reported for the first time. $\mathrm{NH}_{2}\left(\mathrm{CH}_{2}\right)_{6} \mathrm{NH}_{2} \subset \mathrm{CB}[7]$ complex can convert $\mathrm{CO}_{2}$ to bicarbonate product exclusively and faster in solution. The deshielding effect of $\mathrm{CB}[7]$ on the encapsulated amine increases the selectivity for bicarbonate over carbamate and accelerates $\mathrm{CO}_{2}$ fixation towards bicarbonate. Thereby a 
green absorbent to $\mathrm{CO}_{2}$, was provided, regarding high stability, non-corrosiveness and convenient transportation.

\section{ACKNOWLEDGMENTS}

This project was supported by the Fundamental Research Funds for the Central Universities, the National Natural Science Foundation of China (No. 21003123), and a grant from Advanced Programs for the Returned Overseas Chinese Scholars, Ministry of Human Resources and Social Security.

\section{REFERENCES}

[1] C. S. Song, Global challenges and strategies for control, conversion and utilization of $\mathrm{CO} 2$ for sustainable development involving energy, catalysis, adsorption and chemical processing, Catal. Today 115, 2 (2006).

[2] W. Boettinger, M. Maiwald and H. Hasse, Online NMR spectroscopic study of species distribution in MEA-H2O-CO2 and DEA-H2O-CO2, Fluid Phase Equilib. 263, 131 (2008).

[3] P. Tontiwachwuthikul, A. Meisen and C. J. Lim, Solubility of CO2 in 2-amino-2-methyl-1-propanol solutions, J. Chem. Eng. Data 36, 130 (1991).

[4] T. Tsuda, T. Fujiwara, Y. Taketani and T. Saegusa, Amino silica-gels acting as a carbon-dioxide absorbent, Chem. Lett. 2161 (1992).

[5] R. A. Khatri, S. S. C. Chuang, Y. Soong and M. Gray, Thermal and chemical stability of regenerable solid amine sorbent for $\mathrm{CO} 2$ capture, Energy \& Fuels 20, 1514 (2006).
[6] P. Li and L. Liu, Application of Organic Macrocyclic Supramolecular Structures on Adsorption and Conversion of Carbon Dioxide, Prog. Chem. 22, 1940 (2010).

[7] J. Lagona, P. Mukhopadhyay, S. Chakrabarti and L. Isaacs, The cucurbit[n]uril family, Angew. Chem., Int. Ed. 44, 4844 (2005).

[8] W. L. Mock, T. A. Irra, J. P. Wepsiec and T. L. Manimaran, Cycloaddition induced by cucurbituril - a case of pauling principle catalysis, J. Org. Chem. 48, 3619 (1983).

[9] B. C. Pemberton, R. Raghunathan, S. Volla and J. Sivaguru, From containers to catalysts: supramolecular catalysis within cucurbiturils, Chem.-Eur. J. 18, 12178 (2012).

[10] H. Xu and D. M. Rudkevich, CO2 in supramolecular chemistry: Preparation of switchable supramolecular polymers, Chem.-Eur. J. 10, 5432 (2004)

[11] V. Stastny and D. M. Rudkevich, Separations using carbon dioxide, $J$. Am. Chem. Soc. 129, 1018 (2007).

[12] A. Day, A. P. Arnold, R. J. Blanch and B. Snushall, Controlling factors in the synthesis of cucurbituril and its homologues, J. Org. Chem. 66, 8094 (2001).

[13] L. Liu, N. Zhao and O. A. Scherman, Ionic liquids as novel guests for cucurbit[6]uril in neutral water, Chem. Commun. 1070 (2008)

[14] N. Zhao, L. Liu, F. Biedermann and O. A. Scherman, Binding studies on $\mathrm{CB}[6]$ with a series of 1-alkyl-3-methylimidazolium ionic liquids in an aqueous system, Chem.-Asian J. 5, 530 (2010). 